ARTíCULOS DE INVESTIGACIÓN

\title{
Inconstitucionalidad del artículo 94 bis del Código Penal, que establece la imprescriptibilidad de la acción penal respecto a ciertos delitos sexuales cometidos contra menores de edad
}

\author{
Unconstitutionality of article 94 bis of the Chilean Criminal Code, \\ which exempts certain sexual offenses against minors from the statute \\ of limitations
}

\author{
Pablo Castillo Montt \\ Universidad del Desarrollo, Chile
}

RES UMEN

El trabajo analiza la constitucionalidad del artículo 94 bis del Código Penal (CP) a la luz de la fundamentación entregada durante la tramitación de la Ley 2I.I6o para justificar la eliminación de los plazos de prescripción de un catálogo de delitos sexuales que involucran a menores de edad. Para efectos del análisis, el trabajo presenta las concepciones actuales de la institución de la prescripción en derecho penal y propone adoptar la teoría desarrollada por Martin Asholt en Alemania, según la cual la prescripción es consecuencia de un proceso objetivo de pérdida de relevancia penal del injusto. El trabajo también expone de manera crítica la razón central que motivó la introducción del artículo 94 bis CP: la idea de que la víctima tendría un derecho a la imprescriptibilidad de la acción penal en razón de que la interacción sexual con un menor produce, frecuentemente, graves y duraderas afecciones biosicológicas que le impiden denunciar el hecho hasta su recuperación biosíquica, lo que, en general, solo podría ocurrir muy avanzada su edad adulta y con ayuda terapéutica.

\section{PALABRAS CLAVE}

Imprescriptibilidad · delitos sexuales contra menores de edad · constitucionalidad · artículo 94 bis.

\section{AB S T RACT}

This article analyses the constitutionality of article 94 bis of the Chilean Criminal Code based on the arguments given during the making process of Law 
2I.I60 to justify the elimination of the statute of limitations regarding a cata$\log$ of sexual offenses that involve minors. To conduct the analysis, the article presents the actual understanding of the statute of limitations in criminal law and suggests the adoption of Martin Asholt's theory, developed in Germany, according to which, statutes of limitations are a consequence of an objective process consisting in the loss of criminal relevance of the offense. The article also critically shows the main reason that led to the creation of the article 94 bis: the idea that the victim has a right to imprescriptibility on grounds that the sexual interaction with minors usually generates grave and long-lasting biopsychological damages that make it impossible for the victim to denounce the offense until healing occurs, which generally only can take place advanced into adult age and with help of therapeutic assistance.

\section{KEY WORDS}

Imprescriptibility · sexual offences against underage children · article 94 bis . constitutionality.

\section{Razones subyacentes al artículo 94 Bis del Código Penal}

El proyecto que estableció el artículo 94 bis del Código Penal se basó en la idea de que la gravedad de los hechos — similar a delitos de lesa humanidad-, así como sus consecuencias psicológicas, justificarían una excepción al régimen general de prescripción, ya que faltaría la renuncia de la víctima a la acción penal que supone la prescripción, por lo que las víctimas debían conservar su derecho a la justicia. ${ }^{\mathrm{I}}$

Adicionalmente, se afirmó que la medida aumentaría el efecto disuasivo, ${ }^{2}$ y se invocó la tendencia comparada a declarar la imprescriptibilidad de estos delitos, ${ }^{3}$ así como la Convención de los Derechos del Niño, ${ }^{4}$ que obligaría al Estado chileno a establecer la imprescriptibilidad para garantizar el derecho de la víctima a la justicias y posibilitar su reparación. ${ }^{6}$

\section{Fundamento de la prescripción en el Código Penal}

\section{La prescripción a fines del siglo XIX según la doctrina en Chile y España}

Durante la época de redacción del Código Penal, la prescripción se consideraba como una institución imprescindible del derecho penal, ${ }^{7}$ derivada

${ }^{1}$ Biblioteca del Congreso Nacional de Chile, Historia de la Ley 21.16o. Declara imprescriptibles los delitos sexuales cometidos contra menores de edad, p. 3 .

${ }^{2}$ Ibid., p. 47.

3 Ibid., p. 38.

${ }^{4}$ Ibid., p. 155.

5 Ibid., p. I89.

${ }^{6}$ Ibid., p. 52.

7 Pacheco, Joaquín Francisco, El Código Penal concordado y comentado (5. ${ }^{a}$ edición, 
de exigencias de justicia ${ }^{8}$ y humanidad, ${ }^{9}$ cuya inexistencia afectaría perpetuamente los derechos de las personas. ${ }^{10}$

El fundamento del efecto del transcurso del tiempo sobre la responsabilidad penal se veía en la desaparición del suceso de la conciencia social $\mathrm{y}$, en consecuencia, de la justicia y utilidad del castigo, ${ }^{\mathrm{II}}$ ya que el tiempo calmaba los ánimos ${ }^{12} \mathrm{y}$ hacía desaparecer la gravedad del caso. ${ }^{13}$ En consecuencia, el castigo extemporáneo pasaba a ser un mero acto de crueldad, ${ }^{14}$ ya que se estaría sancionando a una persona que ha sufrido las consecuencias de su conducta ${ }^{15}$ y que, probablemente, se ha corregido. ${ }^{16}$

\section{Historia de la regulación de la prescripción en el Código Penal}

Los criterios que se tuvieron en cuenta para diseñar la institución durante las sesiones de la comisión redactora del Código Penal permiten entender que se la consideraba un principio del derecho penal autónomo, con una lógica propia. ${ }^{17}$

En dicha lógica, la institución no admitía excepciones, ni plazos desproporcionados, como lo demuestra la decisión de fijar el inicio del cómputo del plazo al momento de comisión del delito, y no de su descubrimiento $;^{18}$ la decisión de imponer un plazo de prescripción absoluto a la

Madrid, Imprenta y Fundición de Manuel Tello, I88I) I, p. 528; Vera, Robustiano, Código Penal de la República de Chile comentado (Santiago, Imprenta de P. Cadot y C.a, I883), p. 269; Vicente y Caravantes, José, Código Penal reformado: Comentado novísimamente, precedido de una breve reseña histórica del derecho penal de España, y seguido de tablas sinópticas (Madrid, Librerías de Ángel Calleja, I85I), p. $27 \mathrm{I}$.

${ }^{8}$ Pacheco, Joaquín Francisco, cit. (n. 7), p. 530.

9 Vicente y Caravantes, José, cit. (n. 7), p. $27 \mathrm{I}$.

Io Vera, Robustiano, cit. (n. 7), p. 269.

${ }^{\text {II }}$ Pacheco, Joaquín Francisco, cit. (n. 7), p. 529; Vera, Robustiano, cit. (n. 7), p. 273.

${ }^{12}$ Vera, Robustiano, cit. (n. 7), p. 270.

${ }^{13}$ Ibid., p. 270.

${ }^{14}$ Ibid., p. 273; Vicente y Caravantes, José, cit. (n. 7), p. 272.

is Vicente y Caravantes, José, cit. (n. 7), p. 271: «El legislador ha debido tener en cuenta que los remordimientos y la continua agitación que experimenta el culpable, ya por efecto de su delito, ya por sus esfuerzos para evadirse a la acción de la justicia, han debido hacerle sufrir un suplicio no menor».

${ }^{16}$ Vera, Robustiano, cit. (n. 7), p. 269: «El objeto de la pena es prevenir los delitos i quitar al delincuente el que pueda repetirlos. Claro está entonces que aquel que no ha reincidido en un largo, período de años, se ha correjido enteramente teniendo por castigo».

${ }^{17}$ Actas de las sesiones de la Comisión Redactora del Código Penal Chileno (Santiago, Imprenta de la República de Jacinto Núné, I873), p. 44.

${ }^{18}$ Ibid., p. 252. 
acción penal especial del delito de adulterio, ${ }^{19}$ así como la decisión de rechazar un régimen de imprescriptibilidad respecto de personas que se ausentaren del país. ${ }^{20}$

Asimismo, la comisión consideraba que el proceso de prescripción era independiente del efecto que el delito podría tener en la sociedad, según se desprende de la decisión de rechazar el régimen inicial que distinguía cuantitativamente entre la prescripción de la acción y de la pena, sobre la base del nivel de alarma social que producía cada situación. ${ }^{2 \mathrm{~T}}$

Por último, cabe mencionar que, en el diseño de la institución, la comisión también tomó en cuenta la posibilidad de corrección del autor. ${ }^{22}$

\section{Fundamento según la doctrina y jurisprudencia chilena contemporánea}

Conforme a la doctrina mayoritaria en Chile (y en España ${ }^{23}$ ), el fundamento de la prescripción de la acción penal deriva de la necesidad de seguridad jurídica. ${ }^{24}$ Yuseff ${ }^{25}$ — autor de la investigación nacional más acabada sobre el tema- la considera como una institución de orden público (no en interés del delincuente) que garantiza la seguridad jurídica. ${ }^{26}$ Se trataría de una «renuncia (estatal) anticipada, preventiva y legislativa a imponer la sanción en un caso concreto». ${ }^{27}$

19 Ibid., p. 146.

${ }^{20}$ Ibid., p. 25I.

${ }^{21}$ Ibid., p. $25 \mathrm{I}$.

${ }^{22}$ Ibid., p. 297: «...por su buena conducta durante un largo espacio de tiempo se ha hecho digno de recobrar lo que perdió».

${ }_{23}$ Pastor Alcoy, Francisco, Tratado de la prescripción penal (Barcelona, Editorial Atelier, 20I9), p. 94.

${ }^{24}$ Cury Urzúa, Enrique, Derecho Penal. Parte general (8. a edición, Santiago, Ediciones Universidad Católica de Chile, 2005), p. 798; Etcheberry Orthusteguy, Alfredo, Dere-

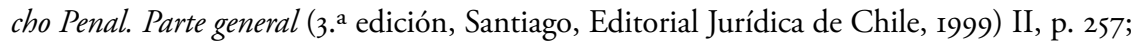
Garrido Montt, Mario, Derecho Penal. Parte general (2. a edición, Santiago, Editorial Jurídica de Chile, 2007), I, p. 388; Guzmán Dálbora, José Luis, Comentario a los artículos 93 a ios del Código Penal, en Politoff Lifschitz, Sergio y Ortiz Quiroga, Luis (dirs.), Texto y comentario del Código Penal Chileno. Libro primero. Parte General (Santiago, Editorial Jurídica de Chile, 2002), I, p. 46i; Matus Acuña, Jean Pierre; Ramírez Guzmán, María Cecilia, Manual de Derecho Penal chileno. Parte general. Limites, presupuestos y consecuencias de la responsabilidad penal en un sistema acusatorio (Valencia, Tirant lo Blanch, 2019), p. I57; Novoa Monreal, Eduardo, Curso de Derecho Penal chileno. Parte General (3. ${ }^{a}$ edición, Santiago, Editorial Jurídica de Chile, 2019), II, p. 402; Yuseff Sotomayor, La prescripción

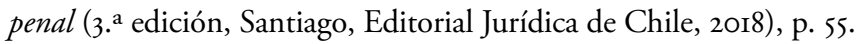

${ }^{25}$ Yuseff Sotomayor, cit. (n. 24), p. 19.

${ }^{26}$ Ibid., p. 55.

27 Ibid., p. 55; Similar en Guzmán Dálbora, José Luis, cit. (n. 24), p. 434. 
En términos similares, la Corte Suprema (y el Tribunal Constitucional español $)^{28}$ considera que la prescripción es un principio general del derecho necesario para consolidar situaciones irregulares, otorgar certeza tanto a presuntas víctimas como a presuntos autores, y evitar la posibilidad de error judicial derivado del desaparecimiento de la prueba de cargo y desCargo. $^{29}$

En un trabajo reciente sobre la materia, CABEZAs ${ }^{30}$ sostiene que la prescripción es consecuencia de un principio de humanidad, ya que una pretensión punitiva temporalmente irrestricta imposibilitaría el desarrollo individual.

\section{REVISIÓN DE LOS FUNDAMENTOS DE LA PRESCRIPCIÓN PENAL}

\section{Explicaciones de la prescripción penal}

a) Seguridad juridica (y probatoria). Difícilmente puede sostenerse que la prescripción sea consecuencia del principio de seguridad jurídica. Un sistema penal temporalmente ilimitado ofrecería igualmente plena seguridad jurídica, en el sentido de que el infractor sabría con seguridad que el ordenamiento jurídico prevé la posibilidad de ser investigado, aprehendido, juzgado y condenado hasta el fin de sus días. ${ }^{3 \mathrm{I}}$

Podría pensarse que el argumento apunta a la adquisición de certeza de la imposibilidad de persecución penal. Sin embargo, dicha certeza no se condice con la finalidad que persigue la idea de seguridad jurídica, ${ }^{32}$ ya que no tiene como objeto normas o posiciones jurídicas ambiguas,

${ }^{28}$ Sentencia del Tribunal Constitucional español número I57 del año I990. Considera a la prescripción como una renuncia estatal a la pena, consecuencia de la seguridad jurídica (artículo 9.3 de la Constitución española) necesaria para un adecuado y rápido (artículo 24.2 de la Constitución española) desenvolvimiento de las relaciones de carácter procesal penal orientadas a la imposición de una pena resocializadora (25.2 de la Constitución española).

${ }^{29}$ Matus Acuña, Jean Pierre, Código penal sistematizado con jurisprudencia (Santiago, Legal Publishing, 20II), p. I67.

30 Cabezas Cabezas, Carlos, Imprescriptibilidad de la acción penal en delitos sexuales contra menores, en Revista de Derecho (Universidad Austral de Chile) 32 (2019), I, p. 279; Biblioteca del Congreso Nacional de Chile, cit. (n. i), p. 64.

${ }^{31}$ Cabezas Cabezas, Carlos, cit. (n. 30), p. 279; Hörnle, Tatjana, Klingbeil, Stefan; Rothbar, Katja, Sexueller Missbrauch von Minderjährigen: Notwendige Reformen im Strafgesetzbuch. [Gutachten] erstellt für den Unabhängigen Beauftragten für Fragen des sexuellen Kindesmissbrauchs (Berlín, 20I3), p. 8; PAstor Alcoy, Francisco, cit. (n. 23), p. 98.

32 Pacheco Gómez, Máximo, Teoría del derecho (4. ${ }^{\mathrm{a}}$ edición, Santiago, Editorial Jurídica, 1993), pp. 449 y ss. 
sino que se refiere a una mera expectativa de resolución de incertidumbre fáctica que no puede fundamentar un límite temporal de los fines del ius puniendi. ${ }^{33}$ Del mero transcurso del tiempo no emana un interés individual legítimo en la certeza de impunidad (inexistente al momento de realización del injusto) que pueda contraponerse y limitar los intereses en la realización de los fines de la pena. ${ }^{34}$

Lo anterior podría reforzarse argumentando que el intervalo de latencia penal operaría como equivalente funcional de la pena, sin embargo, dicho efecto es, en primer lugar, sumamente contingente ${ }^{35} y$, en segundo término, mínimamente equiparable a la pena, puesto que no surte un efecto preventivo general ni especial, ya que no ha existido un acto institucional que confirme la realidad de la conminación penal ni la vigencia de la norma infringida, ni aporta nada a la resocialización del autor.

Del mismo modo, el frecuente argumento relativo a la necesidad de evitar los problemas probatorios y errores judiciales que produciría el transcurso del tiempo ${ }^{36}$ no podría explicar por qué los términos de prescripción se construyen sobre la base de la magnitud del injusto, en vez de la probabilidad de desvanecimiento de la prueba. Igualmente, el desarrollo tecnológico actual en materia de investigación hace que el argumento pierda relevancia como pilar central de la institución. ${ }^{37}$

b) Limites intrinsecos a los fines de la pena. Partiendo de la base de que los fines del proceso de conminación, persecución, enjuiciamiento y ejecución penal son de carácter preventivo general y especial, podría pensarse que es ahí donde deben encontrarse los límites temporales de la potestad punitiva.

En primer lugar, cabe descartar que la teoría de la prevención general negativa contenga un límite temporal inmanente al ius puniendi. No es necesario aquí profundizar sobre la tendencia al exceso inherente a la prevención general negativa ${ }^{38}$ y que se reproduce a propósito de la prescripción, ya que el razonamiento disuasivo habla más bien a favor de la imprescriptibilidad de todo delito. ${ }^{39}$

33 Pastor Alcoy, Francisco, cit. (n. 23), p. 99.

${ }_{34}$ Asholt, Martin, Verjährung im Strafrecht: Zu den theoretischen, historischen und dogmatischen Grundlagen des Verhältnisses von Bestrafung und Zeit in $5 S 78$ ff. StGB (Tübingen, Mohr Siebeck, 20I6), pp. IO5 y ss.

35 Yuseff Sotomayor, cit. (n. 24), p. 54.

${ }^{36}$ Pastor Alcoy, Francisco, cit. (n. 23), p. 85 .

37 Asholt, Martin, cit. (n. 34), p. 93.

${ }^{38}$ Feijoo SÁnchez, Bernardo, Retribución y prevención general. Un estudio sobre la teoría de la pena y las funciones del derecho penal (Montevideo, Editorial B de F, 2007), p. 156.

39 Asholt, Martin, cit. (n. 34). p. I3I; Hörnle, Tatjana, Klingbeil, Stefan; Roth- 
En segundo lugar, podría pensarse que el transcurso del tiempo erradica el suceso de la conciencia social de forma que, en algún momento, cesa la necesidad de confirmar la vigencia de la norma infringida..$^{{ }^{\circ}} \mathrm{El}$ problema de este planteamiento es que, en una sociedad masiva, la gran mayoría de los hechos delictivos no ingresan siquiera a la conciencia colectiva, de forma que su olvido ni siquiera es posible. ${ }^{4 \mathrm{I}}$ Por lo demás, no permite explicar por qué el plazo de prescripción comienza a correr desde la realización del injusto (en vez de su descubrimiento), ni puede explicar la prescripción de la acción respecto de delitos que perduran largamente en la conciencia colectiva. ${ }^{42}$

Por último, podría buscarse un límite temporal en la prevención especial, asumiendo que el transcurso del tiempo sin reincidencia por parte del delincuente permite presumir su resocialización. ${ }^{43}$ En principio, la idea es sensata, pero es dudoso que ese sea el criterio que inspire el sistema, ya que no existe correlación alguna entre el transcurso el tiempo y el arrepentimiento o resocialización del autor, ${ }^{44} \mathrm{y}$ bien puede que el sujeto haya delinquido posteriormente sin que sea (todavía) descubierto. ${ }^{45}$

c) Condición del correcto funcionamiento de la administración de justicia. Varios autores sostienen hoy en día en Alemania ${ }^{46}$ y España ${ }^{47}$ que la prescripción es una herramienta de optimización de los recursos estatales, debido a que el sistema de justicia carece de capacidad para procesar todas las causas que generaría la inexistencia de la prescripción. Sin embargo, el problema de esta forma de entender la prescripción es que no otorga criterios interpretativos y da por supuesta la legitimidad de una potestad punitiva temporalmente ilimitada..$^{8}$

BAR, Katja, cit. (n. 3I), p. I2.

${ }^{40}$ Hörnle, Tatjana, Klingbeil, Stefan; Rothbar, Katja, cit. (n. 48), p. i2; Pastor Alcoy, Francisco, cit. (n. 3I), p. II3.

${ }^{41}$ Asholt, Martin, cit. (n. 34), p. I44; Hörnle, Tatjana, Kuingbeil, Stefan; RothBAR, Katja, cit. (n. 3I), p. 8.

${ }^{42}$ Asholt, Martin, cit. (n. 34), p. I44.

${ }^{43}$ Ibid., p. II8; Yuseff Sotomayor, cit. (n. 24), p. 54.

${ }_{44}$ Asholt, Martin, cit. (n. 34), p. in8. Yuseff Sotomayor, cit. (n. 24), p. 54; Pastor Alcoy, Francisco, cit. (n. 23), p. II5.

${ }^{45}$ Asholt, Martin, cit. (n. 34), p. I23.

${ }^{46}$ Hörnle, Tatjana, Klingbeil, Stefan; Rothbar, Katja, cit. (n. 3I), p. I2.

47 Pastor Alcoy, Francisco, cit. (n. 23), pp. IO3 y ss.

${ }^{48}$ Asholt, Martin, cit. (n. 34), p. 168. 


\section{Prescripción de la acción penal como pérdida} de relevancia penal del injusto

A continuación, se presenta el planteamiento de Martin Asholt, quien pretende superar las teorías que sindican fenómenos contingentes que tienen lugar en el tiempo — resocialización, restablecimiento de la paz social, desaparición de la prueba- como fundamento de la prescripción, proponiendo en vez una relación directa entre el transcurso del tiempo y la responsabilidad penal, afirmando que es el tiempo en sí lo que produce efectos en el derecho penal.

La idea se puede resumir de la siguiente forma: la institución de la prescripción penal constituye una herramienta de selección del pasado jurídicamente pertinente, cuyo fundamento radica en la pérdida de relevancia del injusto concreto para el sistema penal producto del transcurso del tiempo. En el momento en que se realiza el injusto penal nace una relación jurídica singular entre el Estado y el autor. En la medida en que esa relación jurídica permanece inactiva, comienza a distanciarse temporalmente del sistema jurídico, perdiendo progresivamente su relevancia. Alcanzando un cierto momento, la relación jurídica se torna irrelevante para el sistema penal, y el hecho pasa a integrar la historia criminal, sin que ello afecte la vigencia de la norma infringida ni la antijuridicidad de la conducta.

a) Prescripción como herramienta de selección temporal del sistema penal. El planteamiento arranca de la constatación de que el tiempo es un elemento estructural del derecho, en vez de algo externo en lo que simplemente el derecho ocurre. ${ }^{49}$ Esta temporalidad inherente al ordenamiento jurídico se puede observar en numerosas instituciones tanto de derecho público como privado. ${ }^{5 \circ}$

En todo caso, la estructura temporal del derecho nada dice sobre la naturaleza o concepto del tiempo en el ordenamiento jurídico, ya que existen diversos modelos teóricos para explicar el fenómeno. Mientras algunos planteamientos entienden el tiempo como un orden universal abstracto e independiente de lo que ocurre en él, otros distinguen diversas dimensiones temporales (psicológica, social, histórica, etcétera). ${ }^{\text {sI }}$ Incluso

49 Asholt, Martin, cit. (n. 34), p. I82.

so Ibid., p. I8I y 2IO. Por ejemplo, la axiomática relación secuencial entre conflicto jurídico y sentencia judicial, la edad como requisito de adquisición y ejercicio de ciertos derechos, los plazos en el derecho civil, los períodos legislativos, etcétera.

${ }_{51}$ Asholt, Martin, cit. (n. 34), p. 204. Conforme a la teoría de la relatividad, el tiempo no constituye una variable externa e independiente de los procesos físicos, sino una variable interna de la realidad (espacio-tiempo). Otros planteamientos (Bergson) suman a 
se llega a negar su existencia objetiva, asignándole una naturaleza puramente cultural..$^{2}$

Dada la plasticidad conceptual del fenómeno, AsHoLT ${ }^{53}$ intenta articular el concepto de tiempo que subyace a la prescripción penal. Para ello, emplea el modelo temporal de la teoría de sistemas que tiene su origen en el modelo de tiempo planteado por HusserL.

Según Husserl, la persona no experimenta el tiempo puntualmente (en nanosegundos), sino en unidades de sentido. El presente consiste en un intervalo de conciencia, compuesto por un conjunto de sucesos retenidos y anticipados, cuyo contenido y extensión vienen condicionados por el interés actual de la conciencia. ${ }^{54}$ Esta idea se ilustra bastante bien cuando uno analiza la experiencia de escuchar una pieza musical o la participación en una conversación. Dichos sucesos no se experimentan como una secuencia de hechos aislados, sino como unidades de sentido. El auditor y el interlocutor retienen en su conciencia una serie de notas o palabras pasadas, y anticipan las venideras. 55

En consecuencia, para la persona, el presente constituye un "presente extendido", conformado por retenciones y protensiones. ${ }^{56}$ Los sucesos que han abandonado la conciencia pasan a conformar el pasado. ${ }^{57}$

Por su parte, LUHMANN observa que los sistemas sociales operan de manera similar a la conciencia individual, con la diferencia de que el sistema - en este caso, penal — carece de conciencia y memoria natural, por lo que requiere diseñar su propio tiempo. Esta necesidad viene dada por las limitaciones propias del sistema: no dispone de toda la información pasada y, aun cuando así fuera, no le sería posible procesarla. En este esquema, la prescripción representa el mecanismo mediante el cual el ordenamiento jurídico autónomamente restringe la pertinencia de sucesos pasados. ${ }^{58}$

Adicionalmente, Asholt incorpora las reflexiones de Kelsen relativas a los límites temporales de la imputación personal, según las cuales el

la dimensión cuantitativa del tiempo (tiempo medible), una dimensión cualitativa (intervalos de conciencia). Véase también Thier, Andreas, Time, Law, and Legal History. Some Observations and Considerations, en Rechtsgeschichte. Legal History 25 (2017), p. 2I.

${ }_{52}$ Asholt, Martin, cit. (n. 34), p. 22I. Los estudios etnológicos demuestran la variedad de concepciones de tiempo en distintas culturas. Incluso existen grupos en el Amazonas que carecen de noción alguna de tiempo.

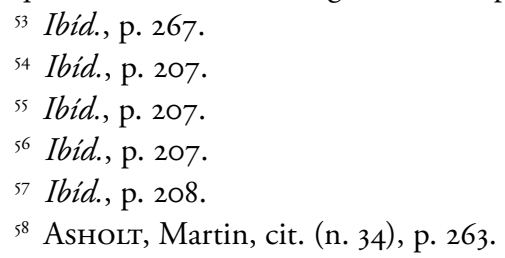


concepto jurídico de persona - reflejo normativo del ser, que posibilita la atribución de sucesos pasados al ser presente- también comprendería la dimensión temporal del «yo», de forma que la posibilidad de imputar conductas pasadas al ser presente encontraría un límite temporal derivado de la transformación del «yo» a través del tiempo. 59

Estas consideraciones llevan a AsHoLT a entender la prescripción penal como una herramienta de selección temporal. Con ella, el sistema limita el horizonte retrospectivo, declarando la impertinencia de sucesos pasados para efectos de imputación penal actual a una persona, fijando así la extensión del presente del sistema penal. ${ }^{60}$

b) El objeto afectado por el tiempo. Para explicar concretamente aquello que resulta impactado por el transcurso del tiempo, Asholt emplea la distinción entre idea de derecho, derecho positivo y derecho concreto, como planos jurídicos con niveles de concreción y sensibilidad temporal diferentes.

La idea de derecho se encuentra en un plano suprapositivo y comprende principios generales abstractos, atemporales y ahistóricos. ${ }^{61}$ Por su parte, el derecho positivo se puede entender como el resultado de la concreción de la(s) idea(s) de derecho a través del proceso legislativo. A través de la positivización, el derecho ingresa a la dimensión temporal, perdiendo parcialmente su atemporalidad y universalidad, y pasa a tener validez para un tiempo y lugar determinado. ${ }^{62}$ En este plano, el derecho es reconocible y vinculante, pero aún no despliegan efectos con respecto a una situación concreta; es tan solo una posibilidad. ${ }^{63}$ Por último, el derecho adquiere realidad completa mediante la aplicación del derecho positivo a un caso concreto, ya sea a través de una sentencia judicial, un contrato, acciones concluyentes, etcétera. ${ }^{64}$ Solo en ese momento el plano normativo se acopla íntegramente con el mundo y adquiere realidad plena, dando nacimiento a una relación jurídica definida que queda fijada espaciotemporalmente en la realidad social. ${ }^{65}$

Correlativo a su grado de concreción, cada uno de estos planos del

59 Ibid., p. 265. Idea también presente durante la tramitación en BIBLIOTECA DEL Congreso Nacional de Chile, cit. (n. i), p. i3.

${ }^{60}$ Asholt, Martin, cit. (n. 34), p. 28I.

${ }^{61}$ Ibid., p. 249.

${ }^{62}$ Ibid., p. 25I. Por ejemplo, los derechos humanos serían concreción positiva de la idea de derecho, sin embargo, pese a su pretensión de universalidad y atemporalidad, tienen vigencia temporal y espacial limitada.

${ }_{63}$ Ibid., p. 250.

${ }^{64}$ Ibid., p. 260.

6s Ibid., p. 250. 
derecho exhibe una sensibilidad temporal distinta. Mientras la idea de derecho pareciera ser atemporal (lex aeterna) y el derecho positivo encierra una pretensión de vigencia indeterminada, el derecho concreto, vale decir, las relaciones jurídicas individuadas son considerablemente más sensibles al transcurso del tiempo. ${ }^{66}$

En derecho penal, la realización del injusto punible - momento en que nace la pretensión punitiva estatal concreta- representa el tercer plano de concreción ${ }^{67} \mathrm{y}$, en definitiva, el objeto respecto al cual el transcurso del tiempo surte efecto. El tiempo no afecta la idea de derecho subyacente a la norma penal, ni la vigencia de la norma positiva, sino que solamente repercute en la relación jurídica concreta que nace a partir de la conducta punible: la conducta, su carácter injusto (formal y material ${ }^{68}$ ) y la correlativa pretensión punitiva ${ }^{69}$ comienzan a distanciarse temporalmente del sistema, disminuyendo su relevancia progresivamente hasta su extinción. ${ }^{70}$

c) El proceso de pérdida de relevancia penal del injusto concreto. AsHolt describe el proceso de pérdida de relevancia penal del injusto recurriendo a las consideraciones de Hegel relativas a la prescripción civil. ${ }^{71}$ Hegel entiende la posesión como una circunstancia puramente externa que solo adquiere significado (relevancia) mediante «la presencia subjetiva de la voluntad». ${ }^{72}$ A través de la conducta, la voluntad — situada fuera del tiempo- se superpone al mundo temporal. Con la conclusión de la conducta, termina también la conexión entre voluntad y cosa, con lo que ella queda entregada al poder del tiempo para terminar, finalmente, sin dueño. ${ }^{73}$

Aplicando esta idea al derecho penal, Asholt ve en la realización del injusto penal el momento de superposición entre voluntad y mundo que da lugar a una relación jurídico penal. Realizado el injusto, el estado de cosas producido comienza a distanciarse temporalmente (de la voluntad en constante actualización) del autor, perdiendo en algún momento su relevancia. ${ }^{74}$

Pero para Asholt lo determinante no es tanto el distanciamiento tem-

${ }^{66}$ Ibid., p. 259.

${ }_{67}^{67}$ Asholt, Martin, cit. (n. 34), p. 253.

${ }^{68}$ Ibid., p. 280. No solo el injusto como inobservancia de la norma, sino también su dimensión material en el sentido de valoración (graduable) del supuesto de hecho punible.

\footnotetext{
${ }^{69}$ Ibid., p. 260.

70 Ibid., p. 253.

${ }^{71}$ Ibid., p. 27 I.

${ }_{72}$ Ibid., p. 272.

${ }_{73}$ Ibid., p. 272.

${ }^{74}$ Ibid., p. 273.
} 
poral entre conducta y voluntad, sino aquel que ocurre entre el derecho concreto y el resto de los planos del derecho temporalmente menos permeables. ${ }^{75}$ El proceso de prescripción consiste en el distanciamiento temporal continuo que se produce entre el sistema jurídico (siempre) actual y la relación jurídica individuada (fijada en el tiempo). ${ }^{76}$

En consecuencia, la prescripción puede entenderse como reconocimiento institucional del momento en que el injusto concreto pierde relevancia por atravesar el horizonte retrospectivo del sistema jurídico actual. ${ }^{77}$ Como se explicó antes, la conducta no se torna ajustada a derecho; desde la perspectiva del sistema actual, ella sigue siendo antijurídica, solo que ha dejado de ser información jurídicamente pertinente.

En resumen, la prescripción sería el reflejo institucional del efecto del tiempo sobre relaciones jurídicas concretas que, luego de atravesar el umbral del presente extendido del derecho penal, ingresan a la historia criminal del sistema. ${ }^{7}$

d) Plazos de prescripción y ámbito de acción legislativa. La prescripción se caracteriza por configurar los plazos en función de la pena asignada al delito. Esta correlación entre magnitud del injusto penal e intervalo de tiempo necesario para que se extinga la responsabilidad permite entender la institución como un reflejo de la pérdida de relevancia del injusto producto del transcurso del tiempo. De la misma forma en que la privación o restricción de libertad durante un lapso de tiempo proporcional al injusto produce la pérdida de relevancia del injusto para el sistema, ${ }^{79}$ el transcurso (pacífico) del mismo lapso de tiempo produce el mismo efecto. Cuando el legislador decide que un injusto, luego de cumplirse un determinado tiempo de pena, ha perdido relevancia, debe ser coherente con ello al establecer el plazo de prescripción, no pudiendo establecer un horizonte temporal completamente desproporcionado, debiendo existir una proporción entre la amenaza penal y los plazos de prescripción.

Con todo, no existe necesariamente una correspondencia entre los plazos de prescripción establecidos en el derecho vigente y los plazos materiales de pérdida de relevancia penal del injusto; el plazo efectivo puede

75 Ibid., p. 275.

${ }^{76}$ Ibid., p. 279.

77 Ibid., p. 274.

${ }^{78}$ Ibid., p. 282.

79 La pena cumplida no transforma la calificación jurídica del hecho, sino que afecta exclusivamente la relación jurídica concreta, extinguiendo la pretensión punitiva. El artículo 93 número $2 \mathrm{CP}$ menciona el cumplimiento de la pena como causal de extinción de la responsabilidad penal. 
ser mucho mayor. Por ejemplo, bien podría afirmarse que la relevancia del injusto de homicidio supera los diez años previstos por la ley.

Frente a esto, cabe preguntarse por qué el legislador establecería plazos de prescripción inferiores a los necesarios para que el injusto pierda relevancia. La explicación vendría dada por consideraciones pragmáticas adicionales a la progresiva pérdida de relevancia del injusto que justifican un plazo menor. Por ejemplo, el legislador ha estimado que, junto con una disminución considerable de la relevancia penal del injusto, se ha alcanzado la paz social, ha cesado la necesidad de pena, no es posible producir una prueba confiable, ha disminuido o desaparecido la prueba de descargo o el autor ha cambiado. ${ }^{80}$

Lo anterior justifica que pueden alargarse los plazos legales a través de la figura de la interrupción y suspensión, cuando no concurran las circunstancias que justificaron un plazo inferior al tiempo material de pérdida de relevancia del injusto. ${ }^{8 \mathrm{r}}$

En todo caso, debe reconocerse un plazo material máximo de prescripción. ${ }^{82}$ Asholt propone un plazo alrededor de treinta años, ya que constituiría el tiempo que toma en producirse un cambio generacional en la sociedad y, en consecuencia, la pérdida de la relevancia del injusto. Por muy grave que sea el delito, Asholt estima que la relevancia del injusto difícilmente puede superar la barrera de una generación. ${ }^{83}$ (Si bien esto resulta plausible, es difícil afirmar un recambio generacional exclusivamente sobre la base de un intervalo de tiempo. ${ }^{84}$ )

En consecuencia, el legislador debe observar una cierta proporción entre la pena asignada a la conducta y el plazo de prescripción, ${ }^{85}$ que no podría superar el límite derivado de la total pérdida de relevancia penal del injusto.

e) El sistema de prescripción del Código Penal como reconocimiento de la pérdida de relevancia penal del injusto. En primer lugar, el artículo 93 del Código Penal menciona la prescripción como causal de extinción de la responsabilidad penal y no del delito, como lo establecía la redacción original, ${ }^{86}$ lo que daría cuenta de que la institución solo excluye la pertinencia penal del injusto, más no su existencia.

${ }^{80}$ Asholt, Martin, cit. (n. 34), p. 38I.

${ }^{81}$ Ibid., p. 38I.

${ }^{82}$ Ibid., p. 382.

${ }^{83}$ Ibid., p. 443.

${ }^{84}$ Véase la investigación de Mannheim, Karl, El problema de las generaciones, en Revista Española de Investigaciones Sociológicas 62 (1993), pp. 193-244.

${ }^{85}$ Asholt, Martin, cit. (n. 34), p. 44I.

${ }^{86}$ Actas de las sesiones de la Comisión Redactora del Código Penal Chileno, cit. (n. 17), p. 252. 
En segundo término, la correlación entre la magnitud del injusto y el plazo de prescripción ofrece un sólido sustento a la idea de la pérdida de relevancia penal del injusto. En esta línea, también debe considerarse el hecho de que incluso los crímenes conminados con presidio perpetuo (originalmente con pena de muerte) prescriban (artículo 94 inciso segundo CP), lo cual apoya la existencia de un plazo máximo de relevancia penal de todo injusto (de lo contrario, debiesen ser imprescriptibles). También el efecto atenuante que le reconoce el artículo I03 $\mathrm{CP}$ al mero transcurso del tiempo pareciera apoyar la idea del proceso de pérdida de relevancia penal del injusto, así como la regla del artículo ıo4 CP se puede entender como reconocimiento de la pérdida de relevancia del injusto pasado para efectos de la reincidencia.

Como tercer punto, el artículo 95 CP, al establecer el día de comisión del delito como inicio del proceso de prescripción, permite dar sustento a la idea de la fijación temporal de la relación jurídico penal singular. Si esto se relaciona con los artículos IoI y IO2 CP, conforme a los cuales la prescripción aplica a «toda clase de personas» y debe ser «declarada de oficio por el tribunal», se puede concluir que el código considera que se trata de un proceso objetivo, de orden público e independiente de la noticia del delito.

En cuarto lugar, la configuración de la prescripción de la acción penal se puede entender como consecuencia del desinterés del sistema por la eventual responsabilidad del autor, derivado de la pérdida de relevancia penal del injusto realizado. La prescripción hace que la querella sea inadmisible (artículo II4 d) CPP), faculta al Ministerio Público a no iniciar la investigación (artículo I68 CPP) y obliga al juez de garantía a decretar el sobreseimiento definitivo (artículo 250 CPP). El sistema niega simplemente la posibilidad de iniciar una investigación para efectos de atribuir responsabilidad penal al autor, ya que - aun prescindiendo de la idea de transformación de la identidad del autor - la norma no requiere de confirmación de su vigencia, pues no existe una infracción actual, sino que ha perdido relevancia. El hecho de que se conozca la desautorización con posterioridad, en nada afecta la pérdida de relevancia del injusto, vale decir, no produce el mismo efecto que un delito actual, porque su conocimiento no ocurre en abstracto, sino que referido a un punto específico fijado en el tiempo.

Por último, el que la imputación —incluso de forma sutil (artículo 42I, $423 \mathrm{CP}$ ) — de un delito prescrito sea constitutivo de delito (artículo $4 \mathrm{I} 7$ número $2 \mathrm{CP}$ ), punible incluso si se puede probar su ocurrencia (artículo $420 \mathrm{CP}$ ), confirma que el conflicto ha perdido relevancia para el sistema 
y que a la víctima —en cuya conciencia, probablemente, el delito perdura por mucho más tiempo o incluso por siempre_ no le está permitido reingresarlo a la esfera pública.

\section{DERECHO DE LA VÍCTIMA (AL ACCESO) A LA JUSTICIA Y REPARACIÓN}

\section{Sobre la posición juridica de la víctima en el sistema penal}

Durante la tramitación del proyecto de ley, se afirmó, en reiteradas ocasiones y sin mayor explicación, que, en estos casos, la prescripción constituye un obstáculo al derecho (al acceso) a la justicia y al proceso de reparación de la víctima. ${ }^{87}$ Este derecho constituiría «un presupuesto mínimo de todo Estado de derecho, por el cual ese mismo Estado prohíbe la autotutela y asume el uso monopólico de la fuerza, a cambio de disponer un orden institucional por el que las personas pueden acceder a los organismos y mecanismos de justicia como medio ordinario de resolución de los conflictos jurídicos». ${ }^{88}$

\section{El derecho de la víctima (al acceso) a la justicia}

Hace décadas viene desarrollándose en la ciencia jurídica una discusión sobre la posición jurídica de la víctima en el sistema penal. ${ }^{89}$ La pregunta central es si —y en su caso, en qué medida - los intereses de la víctima deben ser considerados en la configuración y operación del sistema penal.9०

Esta discusión se ha visto estimulada en gran parte por el denominado punitivismo o populismo penal. Dado que el término es ya, lamentablemente, un cliché en la literatura penal, no es necesario detenerse mayormente en las características de esta corriente emotivista. ${ }^{9 \mathrm{I}} \mathrm{Al}$ respecto, solo cabe mencionar la exaltación de la víctima, quien frecuentemente se propugna como titular del conflicto penal y de un derecho subjetivo al castigo del autor. ${ }^{92}$ Semejante concepción de la posición jurídica de la víctima en

87 Biblioteca del Congreso Nacional de Chile, cit. (n. I), pp. 9, i7 y i9o.

${ }^{88}$ Biblioteca del Congreso Nacional de Chile, cit. (n. i), p. i89.

89 BADER, Jutta, Legitime Verletzteninteressen im Strafverfahren. Eine kritische Untersuchung der Rechtslage und Vorschläge de lege ferenda (Springer-Verlag, 2019), p. I; Riego, Cristián, La expansión de las facultades de las víctimas en la Reforma Procesal Penal y con posterioridad a ella, en Politica Criminal 9 (2014), I8, p. 668.

90 BADer, Jutta, cit. (n. 89), pp. I y ss.

9r Silva Sánchez, Jesús María, Una crítica a las doctrinas penales de "la lucha contra la impunidad" y del "derecho de la victima al castigo del autor», en Revista de Estudios de la Justicia II (2009), p. 44.

${ }_{92}$ Riego, Cristián, cit. (n. 89), p. 684; Silva Sánchez, Jesús María, cit. (n. 9I), p. 54. 
el derecho penal es muy discutible, ${ }^{93}$ ya que esconde un mero deseo de venganza, impertinente en el derecho penal. ${ }^{94}$

Sin embargo, una relegación absoluta de la víctima no resulta razonable, especialmente frente a delitos que han afectado gravemente a la persona. En esos casos, la víctima tiene un interés legítimo en ser considerada por el sistema penal, de forma que es necesario establecer con claridad qué puede exigir y por qué.

Un problema respecto al cual todavía no se llega a una doctrina pacífica dice relación con el fundamento sobre el cual debiesen construirse los intereses de la víctima. ${ }^{95}$ La postura que motivó la creación del artículo 94 bis CP, ve en la víctima al titular original del conflicto penal, al que el Estado debe reconocer un derecho subjetivo al castigo del autor, como contrapartida a la monopolización del uso de la fuerza. ${ }^{96}$ Pero esta idea presupone un derecho preestatal al castigo, inexistente, ya que, en una situación preestatal, la víctima no tiene nada que pueda asemejarse a un derecho al castigo del delincuente, sino solamente la mera posibilidad de reaccionar violentamente a la agresión. La pena estatal es esencialmente distinta a la mera irrogación de un daño, ya que tiene una función normativa y de carácter general, que solo es posible cuando existe un Estado. ${ }^{77}$

Dogmáticamente más convincente es entender que el fundamento de la pretensión de la víctima concreta deriva del reconocimiento constitucional de la dignidad humana. Un ser humano que ha sufrido un daño significativo en su persona puede legítimamente exigir al Estado ser considerada tanto en el diseño del sistema penal como en el desarrollo de la actividad persecutoria y jurisdiccional, para velar por una investigación acuciosa de la responsabilidad del autor por el hecho y una sentencia conforme a la ley. ${ }^{98}$

A grandes rasgos, se admite que el Estado no puede configurar y operar el sistema penal con total prescindencia de la víctima y el daño que esta ha sufrido. En consecuencia, debe permitirle participar en el proceso para

${ }_{93}$ Weigend, Thomas, „Die Strafe für das Opfer«? Zur Renaissance des Genugtuungsgedankens im Straf- und Strafverfahrensrecht, en Zeitschrift für rechtswissenschaftliche Forschung, (Baden-Baden, 20IO), p. 40; BADER, Jutta, cit. (n. 89), p. 70.

94 Silva Sánchez, Jesús María, cit. (n. 9I), pp. 46 y 54; Weigend, Thomas, cit. (n. 93), p. 43 .

95 Bader, Jutta, cit. (n. 89), pp. 201 y ss.

${ }^{6}$ Hörnle, Tatjana, Klingbeil, Stefan; Rothbar, Katja, cit. (n. 3i), p. 50.

97 Weigend, Thomas, cit. (n. 93), p. 45.

${ }_{98}^{8}$ Bader, Jutta, cit. (n. 89), p. I4; MeIer, Bernd-Dieter, Strafrechtliche Sanktionen (2. ${ }^{\text {a }}$ edición, Berlín, Springer, 2006), p. 35 s.; Hörnle, Tatjana, Klingbeil, Stefan; Rothbar, Katja, cit. (n. 3I), p. 49; Weigend, Thomas, cit. (n. 93), p. 5I. 
efectos de aportar prueba, controvertir la versión del imputado y verificar que la persecución y sentencia se ajusten a la ley, vale decir, que el castigo sea proporcional a la medida del injusto y culpabilidad del autor, y que el daño sufrido por la víctima sea considerado en la determinación de la pena. ${ }^{99}$ Todo lo demás permanece como un asunto fundamentalmente estatal. ${ }^{100}$

Excederse en la consideración de los intereses de la víctima podría llevar a modificar el carácter indiscutiblemente público del derecho penal ${ }^{101}$ transformándolo en un sistema de venganza institucionalizada. ${ }^{102}$ Esto no es nada nuevo en el ámbito nacional y fue recogido en gran medida en la reforma del sistema procesal penal. Una de sus preocupaciones centrales era promover los intereses de la víctima, vale decir, reparación, protección y participación en el proceso penal, ${ }^{103}$ pero no como titular de un derecho subjetivo al castigo, sino como colaborador para dotar a la persecución penal de mayor eficacia, ${ }^{104}$ controlando la (in)actividad del Ministerio Público con el fin de evitar la burocratización del procedimiento y las reacciones estandarizadas frente a constelaciones de casos similares. ${ }^{\text {105 }}$

Finalmente, cabe mencionar que el Tribunal Constitucional -al igual que el Tribunal Constitucional español ${ }^{106}$ y el Tribunal Federal Consti-

99 Bader, Jutta, cit. (n. 89), p. 60; Meier, Bernd-Dieter, cit. (n. 98), p. 37; Weigend, Thomas, cit. (n. 93), p. 5 I.

ioo Weigend, Thomas, cit. (n. 93), p. 52; Bader, Jutta, cit. (n. 89), p. 70; Meier, Bernd-Dieter, cit. (n. 98), p. 36.

ror Jakobs, Günther, Derecho Penal. Parte general. Fundamentos y teoría de la imputación (2. ${ }^{\mathrm{a}}$ edición, Madrid, Marcial Pons, 1997), p. I2.

${ }_{102}$ Weigend, Thomas, cit. (n. 93), p. 53. Con amplias referencias, n. 63. Walter, Tonio, Vergeltung als Strafzweck. Prävention und Resozialisierung als Pfichten der Kriminalpolitik, en ZIS 7 (20II), p. 646; Roxin, Claus, Derecho Procesal Penal (25. . edición, Buenos Aires, Ediciones del Puerto, 2000), p. 575.

${ }^{103}$ Riego, Cristián, cit. (n. 89), p. 670.

${ }^{104}$ Horvitz Lennon, María Inés y López Masle, Julián, Derecho Procesal Penal Chileno (Santiago, Editorial Jurídica de Chile, 2002) I, p. 284.

105 Ibid., p. 29 I s.

ro6 Sentencia del Tribunal Constitucional español número 178 del año 200ı: «La pretensión punitiva de quien ejercita la acusación, como persona agraviada, no obliga al Estado, como único titular del ius puniendi, a castigar en todo caso, pues la Constitución no otorga a los ciudadanos un pretendido derecho a obtener condenas penales»; sentencias I57/1990 y 4I/1997: «en modo alguno puede confundirse el derecho a la jurisdicción penal para instar la aplicación del ius puniendi, que forma parte del derecho fundamental a la tutela judicial efectiva, con el derecho material a penar, de exclusiva naturaleza pública y cuya titularidad corresponde al Estado». 
tucional alemán ${ }^{107}$ - ha reconocido y delimitado el interés de la víctima «en que se haga justicia» (artículo 83 inciso segundo de la Constitución Política), ${ }^{108}$ el cual obliga exclusivamente al legislador a diseñar el procedimiento penal de forma que contemple la posibilidad de que la víctima lleve adelante — siempre bajo control judicial — la persecución penal y que pueda recurrir a la judicatura frente a decisiones del Ministerio Público que hagan cesar arbitrariamente la pretensión punitiva, puesto que ello perjudicaría el interés público en la persecución. ${ }^{109}$

\section{Prescripción como vulneración del derecho de la víctima}

a) El argumento. La discusión parlamentaria se estructuró conforme a una lógica que ve la prescripción penal como la prescripción del derecho de la víctima, y se argumentó que ese derecho no podría prescribir en estos casos, ya que la conducta del autor dejaría a la víctima imposibilitada para denunciar el hecho. ${ }^{\text {Iо }}$

La incapacidad de denuncia se explicó de distintas formas, afirmándose, por una parte, que la víctima menor de edad no es capaz de comprender la connotación sexual del acto ni el daño que ha sufrido, además de la frecuente cercanía del autor al círculo familiar del menor. ${ }^{\text {III }}$

Por otra parte, se afirmó que la causa de la incapacidad de denuncia se debe a la "disociación experimentada por la víctima»" ${ }^{\text {II2 }}$ o que ella "reprima el recuerdo de la agresión». ${ }^{\text {I’3 }} \mathrm{El}$ abuso sexual en menores dañaría el hipocampo, lo que haría que el recuerdo quede «escindido de la corteza cerebral que es la que hace que aparezca la memoria de manera inmediata, y es por ello que ocurre el fenómeno de los desencadenantes, porque para que la persona recuerde tiene que tener un evento que le haga reminiscencia, que le reconecte su corteza con su zona hipotalámica, momento en que comienzan los flash back y empiezan a recuperar la historia». ${ }^{\mathrm{II} 4}$ Esto generaría un «obstáculo biológico y cerebral para relatar plenamente lo

${ }_{107}$ En 2 BvR I45I/OI, Rn. (I-4) y BVerfGE 5I, I76 (I87) se niega una pretensión constitucionalmente garantizada a la persecución penal de un tercero mediante el Estado.

${ }^{108}$ Considerando Iundécimo de la sentencia del Tribunal Constitucional del 28 de noviembre de 20I9, causa rol 6718-I8-INA.

${ }^{\circ}$ Ibid. Considerandos noveno a duodécimo.

io Biblioteca del Congreso Nacional de Chile, cit. (n. i), p. 9.

III Ibid., p. 8.

"I2 Ibid., p. I6.

${ }^{113}$ Ibid., p. 66.

${ }^{114}$ Ibid., p. 327. 
padecido" que solo cesa cuando termina el proceso biológico de reparación, ${ }^{\mathrm{II}}$ lo cual ocurriría alrededor de los 45 años. ${ }^{\mathrm{II}}$

La Fundación Amparo y Justicia presentó un documento que explicaría «las razones del tiempo diferente de develación que requieren las víctimas de este tipo de delitos». ${ }^{117}$ Sin embargo, solo uno de los estudios citados — con considerables prevenciones de parte de los autores sobre la confiabilidad de los resultados - ${ }^{\text {in8 }}$ menciona una lista de factores que pueden incidir en el proceso de contar lo sucedido. ${ }^{19}$ El resto de los estudios citados no mencionan consecuencias físicas ni psíquicas que impidan que la víctima denuncie el hecho durante la adultez. ${ }^{120}$ Cabe destacar que uno de los estudios citados da cuenta de que, en el universo de mujeres encuestadas, el tiempo entre el cese del abuso y la develación era de I2,I ańos ${ }^{121}$ y que la edad promedio de develación era 25,9 años, ${ }^{122}$ información omitida por la fundación y que más bien habla en contra de la imprescriptibilidad.

b) Sobre la causalidad entre abuso y daño, y la magnitud del mismo. En primer lugar, cabe destacar la alta cuestionabilidad de que uno o más episodios de abuso sexual pueda generar en la víctima recuerdos reprimidos o períodos de disociación, ya que simplemente no existe evidencia científica que respalde dicha hipótesis. ${ }^{123}$ Tanto es así, que el profesor de psicología

II Ibid., p. I8. «El fundamento radica, precisamente, en el extenso tiempo que demora la víctima en desarrollar biológicamente las condiciones necesarias para efectuar un relato de lo padecido». Similar en Biblioteca del Congreso Nacional de Chile, cit. (n. i), pp. I8 y 24.

in6 Biblioteca del Congreso Nacional de Chile, cit. (n. i), p. 42.

${ }^{117}$ Ibid., p. 92.

"I8 Roesler, T. y Weissmann, T., Telling the Secret. Adult Women Describe Their Disclosures of Incest, en Journal of Interpersonal Violence 9 (1994), 3, p. 329.

"19 Ibid., p. 333.

${ }^{120}$ Alaggia, Ramona, Many ways of telling: expanding conceptualizations of child sexual abuse disclosure, en Child Abuse \& Neglect 28 (2004), pp. I213-I227; Vega A; Romo V; Franco D. y Pérez M., Develación de las experiencias de agresión sexual de presuntas víctimas adultas: una propuesta comprensiva, en Huellas. Cuadernos de Criminodinámicas y Fenómenos Emergentes 2 (2016), pp. I6I-I84. Este último estudio versa sobre víctimas adultas.

${ }^{\text {I2I }}$ Roesler, T. y Weissmann, T., cit. (n. iI8), p. 335.

${ }^{122}$ Ibid., p. 330.

${ }^{123}$ Mcnally, Richard, Debunking Myths About Trauma and Memory, en Can J Psychiatry 50 (2005) I3, p. 821; Patihis, L.; Ho, L. Y.; Tingen, I. W., Lilienfeld, S. O. y Loftus, E. F., Are the "Memory Wars» Over? A Scientist-Practitioner Gap in Beliefs About Repressed Memory, en Psychological Science, 25 (20I4) 2, p. 528 s.; Pendergrast, Mark, The Repressed Memory Epidemic. How It Happened and What We Need to Learn from It (Springer International Publishing, Springer International, 2017), p. 94. 
de la Universidad de Harvard Richard McNally —en una carta dirigida a la Corte Suprema de California— calificó la idea como «la pieza más perniciosa del folclor que haya infectado la psicología y psiquiatría». ${ }^{124}$

En segundo lugar, cabe matizar considerablemente la habitual idea de que el abuso sexual de menores inexorablemente dejaría graves secuelas emocionales y cognitivas, ${ }^{125}$ ya que al respecto existe una gran controversia en el ámbito de la psicología y psiquiatría, ${ }^{126}$ pese a la creencia extendida en la sociedad y el ámbito de la praxis psicológica. ${ }^{127}$

La gran mayoría de los estudios científicos dan cuenta de la posibilidad de que el abuso sexual de menores deje secuelas de gran magnitud, sin embargo, no con la regularidad y magnitud que se afirmó durante la tramitación del proyecto de ley. La conclusión que se repite a lo largo de los estudios científicos sobre la materia es que los efectos que produce el abuso sexual de menores son de naturaleza altamente contingente, y de magnitud extremadamente variable. ${ }^{128}$

${ }^{124}$ Pendergrast, Mark, cit. (n. I23), Prefacio, p. xvii.

${ }^{125}$ Clancy, Susan, The Trauma Myth. The truth about the sexual abuse of children and its aftermath (New York, Basic Books, 2009), p. 7.

${ }^{126}$ Exposición detallada de los inicios y desarrollo de la controversia en MccoY, Monica L. y Keen, Stefanie M. (2014) Child Abuse and Neglect (2. ${ }^{\mathrm{a}}$ edición, New York, Psychology Press, 20I4), p. I8I.

${ }^{127}$ Los estudios que han sentado las bases para la concepción generalizada son ampliamente cuestionados. Oкамі, Paul, Sociopolitical Biases in the Contemporary Scientific Literature on Adult Human Sexual Behavior with Children and Adolescents, en FeIERman, Jay R. (ed.), Pedophilia. Biosocial Dimensions (New York, Springer Verlag, 1990), pp. 91 y ss.

${ }^{\text {r28 }}$ Dallam, S. J., Gleaves, D. H., Cepeda-Benito, A., Silberg, J. L., Kraemer, H. C., \& SPIEgel, D. The effects of child sexual abuse: Comment on Rind, Tromovitch, and Bauserman (1998), en Psychological Bulletin i27 (200I) 6, p. 7I6; Oellerich, Thomas D., Rind, Tromovitch, and Bauserman: Politically incorrect-Scientifically correct, en Sexuality and Culture 2 (2000) 4, p. 67; Ondersma, Steven; Chaffin, Mark; Berliner, Lucy; Cordon, Ingrid; Goodman, Gail; Barnett, D., Sex with Children Is Abuse: Comment on Rind, Tromovitch, and Bauserman (1998), en Psychological bulletin 127 (2001), p. 709; Rind, Bruce; Tromovitch, Philip y Bauserman, Robert, A Meta-Analytic Examination of Assumed Properties of Child Sexual Abuse Using College Samples, en Psychological Bulletin I24 (1998), I, p. 22; Rind, Bruce; Tromovitch, Philip y Bauserman, Robert, The Validity and Appropriateness of Methods, Analyses, and Conclusions in Rind et al. (1998): A Rebuttal of Victimological Critique From Ondersma et al. (200I) and Dallam et al. (200I), en Psychological Bulletin I27 (200I) 6., pp. 753 y ss.; VACHON, David; KRUEger, Robert; Rogosch, Fred y Cicchetti, Dante, Assessment of the Harmful Psychiatric and Behavioral Effects of Different Forms of Child Maltreatment, en JAMA Psychiatry, 72 (2015), p. 5; VAN Duin, E. M.; Verlinden, E.; Vrolijk-Bosschaart, T. F; Diehle, J; Verhoeff, A. P; Brilleslijper-Kater, S. N; y Lindauer, R. J.L., Sexual abuse in very young children: a psychological assessment in the Amsterdam Sexual Abuse Case study, en European Journal of 
En consecuencia, es cuestionable la fundamentación de la imprescriptibilidad de la acción penal de los delitos mencionados en el artículo 94 bis $\mathrm{CP}$ sobre la base de una supuesta imposibilidad de denuncia, ya que, por regla general, los menores víctimas de delitos sexuales, si bien sufren daños que obstaculizan la denuncia, no se ven indefinidamente imposibilitados de denunciar, como se sugirió durante la tramitación del proyecto de ley.

\section{Argumentos adicionales Que SUSTEntaron la MedidA}

En cuanto a la equiparación a los delitos de lesa humanidad, el argumento no puede ser considerado. Aun asumiendo que la interacción sexual con menores de edad indefectiblemente causa secuelas psicológicas graves equiparables a la tortura, la sola magnitud del injusto no alcanza a justificar un régimen de imprescriptibilidad de la acción penal, ${ }^{129}$ ya que el fundamento de la imprescriptibilidad de los delitos de lesa humanidad radica, esencialmente, en su carácter sistemático y en la imposibilidad de persecución producto de la complicidad, aquiescencia u obstaculización gubernamental. ${ }^{130}$

Tampoco debiese considerarse, sin más, que la imprescriptibilidad sea una exigencia en alguna medida derivable de la Convención de los Derechos del Niño. Si bien el artículo I9.I de la Convención establece la obligación de adoptar todas las medidas apropiadas para proteger al niño, ello presupone verificar que la imprescriptibilidad es una medida apropiada de protección (sobre lo inapropiado de la medida, véase el punto 6.2).

\section{RESUMEN GENERAL y ANÁLISIS}

\section{Problemas que subyacen al artículo 94 bis $C P$}

En primer lugar, la medida arranca de un concepto de la institución de la prescripción penal desprovisto de contenido material, que explica su existencia como un acto de indulgencia estatal o, en el mejor de los casos, una concesión de certeza de impunidad. ${ }^{13 \mathrm{I}}$ Dicha comprensión desconoce que la institución obedece primariamente a un proceso objetivo: la disminución progresiva en el tiempo de la relevancia del injusto para el sistema

Psychotraumatology, 9 (2018), I, DOI: I0.1080/20008198.2018.1503524.

${ }_{129}$ Asholt, Martin, cit. (n. 34), p. 460 y ss. Un buen ejemplo, es la imprescriptibilidad del homicidio calificado establecida en 1979 en Alemania, que ha sido criticada fuertemente criticada. Asholt, Martin, cit. (n. 34), p. 448, n. 782.

r3o Cabezas Cabezas, Carlos, cit. (n. 30), p. 282.

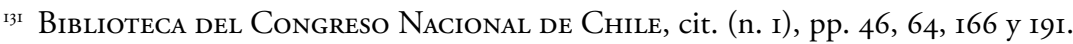


penal que concluye en su desvanecimiento. Igualmente, desconoce que el legislador no puede disponer discrecionalmente de los plazos de prescripción, sino que debe observar una proporción entre la amenaza penal y el plazo de prescripción, y el límite material que representa la pérdida de relevancia del injusto.

En segundo término, la medida se basa en una concepción errada tanto del conflicto penal, como de la posición jurídica de la víctima en el sistema penal. Sugerir que la mera existencia de un plazo de prescripción constituye una afectación de un derecho de la víctima que deba ser justificada es incompatible con los fundamentos del derecho penal como institución esencialmente pública. Ni la víctima tiene un derecho subjetivo al castigo del autor, ni el Estado actúa en representación de la víctima al diseñar y operar el sistema penal.

La potestad punitiva se justifica solo parcialmente en razón de la situación de la víctima. En la etapa de conminación, la relevancia penal de la infracción de una norma de conducta que afecta bienes jurídicos viene dada por razones que trascienden holgadamente al conflicto entre víctima y autor. Lo que justifica el aseguramiento penal de dichas normas de conducta es su relevancia pública. ${ }^{32} \mathrm{Si}$ bien ellas implican una afectación de un bien jurídico de la víctima concreta, lo determinante son las consecuencias probables de su proliferación, ya que afectaría las condiciones generales de vida de los individuos. ${ }^{133}$ Esto es lo que justifica su criminalización y castigo. Dado que el Estado no puede deshacer lo ocurrido, debe orientarse a lograr aquello que sí puede lograr: comunicar la relevancia de la norma de conducta a las personas mediante la conminación penal y confirmar su vigencia en caso de inobservancia mediante la imposición de la pena. ${ }^{34}$

Lo anterior en ningún caso conduce a un derecho penal despersonalizado o colectivista. La perspectiva y criterios que debiesen guiar el diseño y operación del sistema penal incluyen, desde luego, la perspectiva del individuo. Las personas, como titulares de derechos fundamentales, podemos exigir legítimamente al Estado que criminalice — dentro de los límites derivados de las exigencias constitucionales (legalidad, proporcionalidad y culpabilidad) - conductas que afecten nuestros bienes jurídicos. Del mismo modo, en el evento de que seamos afectados por una conducta típica, tenemos derecho a participar activamente en el proceso penal, aportando a la investigación y argumentación, y controlando la

\footnotetext{
${ }^{132}$ JаковS, Günther, cit. (n. IOI), p. I2.

${ }^{133}$ Ibid., pp. 55 y ss.

${ }^{134}$ Ibid., pp. 12 y ss.
} 
arbitrariedad de las decisiones del órgano persecutor y de la judicatura, vale decir, tenemos derecho a exigir que se conduzca una investigación, persecución y condena conforme a la ley que considere razonablemente el daño que hemos sufrido.

Inversamente, no tenemos un derecho subjetivo irrestricto al castigo del autor sobre la base de nuestra apreciación individual de la magnitud del injusto sufrido. La perspectiva pública, de carácter general y objetivo, que requiere la política criminal estatal debe incorporar múltiples perspectivas. Asumiendo que la política criminal se encuentra debidamente fundamentada, nuestra discrepancia con ella no es fundamento suficiente para argüir una privación arbitraria de nuestro derecho, puesto que el sistema penal constituye un sistema público al servicio de diversos intereses y no exclusivamente el que podamos tener como víctimas.

En resumen, las personas tenemos derecho a ser consideradas en el diseño y operación del sistema penal, pero nuestros intereses particulares no son preponderantes, sino que deben ser ponderados y armonizados por el legislador junto al resto de intereses y circunstancias que confluyen al dirigir la política criminal del Estado.

En tercer lugar, la medida se basa en una representación imprecisa de la situación de la víctima. La idea de que la víctima se encuentre absolutamente impedida de accionar penalmente —en términos equiparables a la imposibilidad de accionar frente al injusto sistemático de los delitos de lesa humanidad - es difusa y empíricamente inconsistente.

Durante la tramitación del proyecto no se consideraron siquiera las contundentes objeciones formuladas por parte de un sector importante de la comunidad científica en contra de la idea de la disociación o pérdida de memoria. Tampoco se dio cuenta de la alta contingencia y magnitud variable de las consecuencias psicológicas que pueden afectar a los menores involucrados en interacciones sexuales con adultos. Existiendo una profunda controversia en torno a las consecuencias biosíquicas de los abusos sexuales, no es razonable asumir que, en el común de los casos, produzcan una imposibilidad absoluta de denunciar el hecho.

En relación con este último punto, resulta también errada la indiferenciación de la medida, ya que asume que conductas completamente disímiles generarían efectos psicológicos similares en probabilidad y magnitud que imposibilitan la denuncia. Por ejemplo, resulta cuestionable que la ejecución de acciones de significación sexual en presencia de un menor (artículo 366 quáter CP) pueda generar dicho efecto.

Lo anterior no apunta a desconocer la posibilidad de consecuencias psicobiológicas duraderas, pero su contingencia y variable magnitud im- 
piden afirmar, de forma tan categórica como se hizo en la tramitación de la ley, una imposibilidad absoluta de accionar penalmente. Aun aceptando la premisa de que todas las formas de interacción sexual con menores producen un efecto tan grave en la víctima que esta queda absolutamente imposibilitada de denunciar, no existe un fundamento suficiente que justifique la eliminación de los plazos de prescripción, ya que los daños psicológicos son un cuerpo extraño en el injusto penal, de forma que no inciden en el proceso de prescripción. No existen tipos penales ni circunstancias agravantes que consideren las consecuencias psicológicas que sufre la víctima (salvo quizás el artículo 397 número I CP, cuando la víctima queda «demente»).

En los delitos que afectan bienes jurídicos personalísimos, la relevancia penal de la conducta contraria a derecho se determina fundamentalmente en función de la intensidad objetiva de la afectación. Esto no significa que la integridad psíquica de la persona no sea susceptible de protección penal (ejemplo de ello son las torturas psicológicas previstas en el artículo I50 A inciso tercero $\mathrm{CP}$ ), ni que las consecuencias psicológicas sean totalmente ajenas a la configuración del injusto penalmente relevante, ya que los bienes jurídicos se protegen, precisamente, porque su afectación acarrea múltiples consecuencias negativas para la persona, dentro de las cuales se encuentran las de carácter psicológico. Sin embargo, ya la mera afectación del bien jurídico es penalmente relevante, mientras que los posibles daños psicológicos no influyen en la reacción penal. Su ausencia en nada afecta la punibilidad ni penalidad abstracta de la conducta e, inversamente, su presencia en nada incide en la configuración del injusto. Su concurrencia es una circunstancia contingente que podría ser considerada solo para la graduación de la pena concreta conforme al artículo $69 \mathrm{CP}$.

Tampoco significa negar la contrariedad a derecho de los daños psicológicos derivados de la conducta típica, ni su relevancia para el sistema jurídico, ya que su concurrencia fundamenta una pretensión de reparación para la víctima y dan lugar a la acción indemnizatoria. Es solo que ellos son irrelevantes para dar por realizado el injusto penal. Al derecho penal solo le interesa la afectación objetiva del bien jurídico con independencia de ulteriores consecuencias psicológicas contingentes y variables.

Las diversas formas de interacción sexual con menores de edad sin duda afectan diversos bienes jurídicos: dignidad, indemnidad y autonomía sexual, integridad física y psíquica. Y es la sola afectación lo que justifica su relevancia penal. Desde el momento en que se afectan los bienes jurídicos sin la voluntad de la víctima, la conducta es contraria a derecho 
y penalmente relevante; la estructura típica del injusto carece de un resultado psicológico.

La realización de dicho injusto penalmente relevante determina el momento en que este queda fijado en el tiempo para el sistema penal y, por tanto, el momento en que comienza a perder progresivamente relevancia. En consecuencia, la aparición posterior de daños psicológicos no impacta el proceso de pérdida de la relevancia penal. Desde la perspectiva estatal, el injusto penal nace y se extingue con independencia de las consecuencias psicológicas derivadas de la conducta.

En conclusión, el artículo 94 bis CP sustituyó una regulación sistemáticamente coherente perfectible mediante una leve ampliación del plazo de suspensión (véase lo que decimos sobre el punto más adelante) — por una regulación que contradice profundamente los fundamentos del sistema penal.

\section{Análisis de constitucionalidad del artículo 94 bis $C P$}

a) ¿Satisface el régimen especial de prescripción el estándar de justificación impuesto por el artículo Ig número 2 CPR? Dado que el artículo 94 bis CP introduce en el sistema general de prescripción del código un régimen excepcional aplicable solamente a una constelación determinada de conductas punibles, corresponde analizar si dicho tratamiento diferenciado se encuentra justificado conforme a los estándares que impone el artículo i9 número 2 inciso segundo CPR.

En nuestro ordenamiento jurídico, la regla general es la igualdad de trato de todas las personas que se encuentren en la misma situación. ${ }^{135}$ Toda desviación debe ser justificada conforme a una argumentación racional, que demuestre que el tratamiento diferenciado no es arbitrario, sino que responde a razones reales y de peso, ya que la función principal de la igualdad constitucional es impedir las diferencias de trato injustificadas. ${ }^{136}$

Según se explicó antes, el tratamiento especial de la acción penal emanada de los delitos sexuales cometidos contra menores de edad se apoya en una serie de consideraciones que, examinadas seriamente, no son realmente atendibles como fundamentación de una política criminal estatal del siglo XXI. Apelar a la magnitud del injusto de una serie de conductas de muy dispar gravedad para propugnar un trato excepcionalísimo es inapropiado como justificación, ya que el sistema penal reconoce la prescrip-

${ }^{135}$ Díaz De Valdés Juliá, José Manuel, Igualdad Constitucional y no Discriminación (Valencia, Editorial Tirant Lo Blanch, 2019), p. 83.

${ }^{136}$ Ibid., p. 91. 
ción de la acción penal de una gama de conductas que afectan en extremo bienes jurídicos de suma importancia.

Por otra parte, la víctima no tiene una pretensión en los términos planteados en la tramitación del proyecto, que justifique (mucho menos que exija) que el sistema prescinda completamente de una de las formas de extinción de responsabilidad penal. La relación jurídica que surge a partir de la comisión del delito existe exclusivamente entre el Estado y el autor del hecho, por lo que la existencia de un plazo razonable de prescripción no puede ser conceptualizada como vulneración de una posición jurídica individual. Por último, aun cuando se acepte la cuestionable imposibilidad de denuncia, ella no alcanza a justificar una medida tan extrema, si se compara con una situación análoga: el homicidio — cuyo injusto es, al menos, equivalente - imposibilita absoluta y perpetuamente la posibilidad de la víctima de denunciar y, sin embargo, prescribe.

Como se puede apreciar, el artículo 94 bis CP infringe abiertamente la prohibición constitucional de arbitrariedad establecida en el artículo I9 número 2 inciso segundo $\mathrm{CPR},{ }^{137}$ ya que ninguna de las razones esgrimidas durante la tramitación del proyecto justifica una excepción tan radical al principio general de la prescripción eventual de toda acción penal consagrado en nuestro sistema. ${ }^{138}$

b) Otras garantías constitucionales afectadas por la norma. Debe tenerse en cuenta que la prescripción no beneficia solamente a quien ha delinquido, sino a toda persona que se vea confrontada con una imputación de hechos pasados, los cuales pueden ser completamente verídicos y precisos, pero también pueden ser imprecisos e incluso falsos, por lo que la remoción de plazos de prescripción de la acción penal afecta a un número indeterminado de personas, que en el muy largo plazo (por ejemplo, en cincuenta años más) puedan ser objeto de una denuncia de una persona con quien efectivamente se interactuó sexualmente cuando era menor de edad, pero que la percepción, recuerdo o descripción sea suficientemente imprecisa como para hacer la diferencia en su calificación jurídica.

En consecuencia, la remoción del plazo de prescripción afecta —en el sentido de amenaza ${ }^{139}$ - el derecho fundamental a la honra (artículo is número $4 \mathrm{CPR}$ ) de un número indeterminado de personas, ya que amplía

${ }^{137}$ En contra, sobre la base de un estatuto privilegiado de los menores, BibliotecA del Congreso Nacional de Chile, cit. (n. i), pp. i4, i7, 33 y 46.

${ }^{138}$ En este sentido, pero sin mayor detalle, Hörnle, Tatjana, Kuingbeil, Stefan; RoTHBAR, Katja, cit. (n. 3I), p. 66.

${ }^{139}$ Aldunate Lizana, Eduardo, Derechos Fundamentales (Legal Publishing, Santiago, 2008), p. 230. 
considerablemente las posibilidades de que alguien pueda ser objeto de una imputación imprecisa o falsa. ${ }^{140}$ De la misma forma, afecta la libertad personal (artículo i9 número $7 \mathrm{CPR}$ ), ya que — atendida la realidad del sistema judicial chileno- la imputación por un delito sexual contra menores conlleva una alta probabilidad de ser objeto de medidas cautelares restrictivas o privativas de libertad injustificadas. ${ }^{\text {It }}$ Por último, la medida afecta considerablemente la dimensión material el derecho de defensa (artículo 19 número 3 inciso segundo $\mathrm{CPR}$ ), ya que el transcurso del tiempo dificulta progresivamente la producción de prueba de descargo, ${ }^{\mathrm{I} 42}$ lo que a su vez aumenta el riesgo de error judicial, afectando más aun la libertad personal.

Si bien $\operatorname{casi}^{\mathrm{i}{ }^{143}}$ la totalidad de las finalidades perseguidas por la medida son legítimas (protección de los menores frente a interacciones sexuales antijurídicas y reparación), el artículo 94 bis CP no constituye un medio idóneo, necesario ni proporcional para su consecución, por lo que la afectación de garantías constitucionales derivada de su existencia contraviene el principio de proporcionalidad. ${ }^{\mathrm{I} 4}$

En primer lugar, la medida es manifiestamente inidónea para aumentar la protección de los menores y reparar el daño causado. Si bien no se encontraron estudios que analicen los efectos disuasivos de un aumento en los plazos de prescripción de la acción penal, el sentido jurídico común tradicional ${ }^{145} \mathrm{y}$ el estudio criminológico ${ }^{\mathrm{T} 46}$ indican que un aumento de penas respecto de conductas que ya se encuentran criminalizadas carece de efecto disuasivo, pudiendo aplicarse el mismo razonamiento a este caso. Asimismo, la imprescriptibilidad de la acción tampoco es apta para otorgar reparación psicoemocional a la víctima, ya que el castigo del autor produce en la víctima el efecto contrario al que se tiende a esperar. Si bien

i40 Biblioteca del Congreso Nacional de Chile, cit. (n. i), p. 43.

${ }^{14}$ Ibid., p. 44

${ }^{142}$ En detalle sobre este riesgo Asholt, Martin, cit. (n. 34), pp. 93 y ss.; Asimismo, Hörnle, Tatjana, Klingbeil, Stefan; Rothbar, Katja, cit. (n. 31), pp. 55 y ss.; Yuseff SOTOMAYOR, cit. (n. 24), pp. $52 \mathrm{~s}$.

I43 Salvo aquella que busca satisfacer el «derecho de la víctima» (en el sentido propuesto en la tramitación), ya que contradice la función eminentemente pública del derecho penal consagrada en el artículo 83 de la Constitución.

${ }^{144}$ Sobre el principio de proporcionalidad y sus requisitos Aldunate Lizana, cit. (n. I39), pp. 264 y ss.

I45 Beccaria, Cesare, Tratado de los delitos y de las penas (Madrid, Carlos III University of Madrid, 2015), p. 55.

${ }^{146}$ Feijoo Sánchez, Bernardo, cit. (n. 38), p. I52 s.; Meier, Bernd-Dieter, cit. (n. 98), pp. 27 y ss. 
las investigaciones en los campos de la psicología y criminología demuestran que las personas tienen arraigada la necesidad de retribución frente a conductas que consideran injustas, ${ }^{147}$ los experimentos demuestran que la retribución no contribuye a la superación interna del conflicto por parte de la víctima, sino que la obstaculiza, ya que intensifica el foco de la víctima en el hecho y en el autor. ${ }^{\mathrm{I} 48}$

Como segundo punto, asumiendo la idoneidad disuasiva del artículo 94 bis CP, resulta difícil pensar en una medida preventiva equivalente en eficacia, pero menos gravosa para los derechos fundamentales afectados, por lo que, a este respecto, podría considerarse necesaria. Sí es innecesaria en lo relativo a la finalidad de reparación, ya que el fortalecimiento de un programa de atención a víctimas de delitos sexuales pareciera ser una medida bastante más conducente al bienestar psicoemocional que perpetuar la posibilidad de castigar al autor.

Por último, y aun asumiendo su idoneidad y necesidad, la afectación de derechos fundamentales que implica la medida se encuentra en total desproporción con los beneficios derivados de su existencia. Aumentar la posibilidad de que diversas garantías fundamentales sean afectadas indebidamente en las formas descritas para lograr un efecto preventivo general marginal y una satisfacción psicológica de la víctima no parece justificarse desde la perspectiva de la función del Estado. ${ }^{\text {I49 }}$

Una posibilidad hubiese sido investigar el rango etario en el que las personas en Chile alcanzan usualmente independencia financiera y madurez emocional suficiente como para poder tomar una decisión de denunciar el hecho e incrementar acordemente el plazo de suspensión, por ejemplo, hasta los 25 años, de forma que las personas tengan un margen de tiempo razonable en el que puedan ponderar libremente si desean denunciar. ${ }^{150}$

\section{BibLIOGRAFÍA}

Actas de las sesiones de la Comisión Redactora del Código Penal Chileno (Santiago, Imprenta de la República de Jacinto Núnez, I873).

${ }^{147}$ WALter, Tonio, cit. (n. IO2), pp. 636.

${ }^{148}$ En detalle Walter, Tonio, cit. (n. IO2), pp. 638-64I. Carlsmith, Kevin M., Wilson, Timothy D., GILBERT, Daniel T., The paradoxical consequences of revenge, en Journal of Personality and Social Psychology 95 (2008), 6, pp. I316-1324; JACKson, Joshua C.; CHOI, Virginia K., Gelfand, Michele J. (2019), Revenge: A Multilevel Review and Synthesis, en Annual Review of Psychology 70 (2019), pp. 319-321.

I49 En este sentido, Biblioteca del Congreso Nacional de Chile, cit. (n. i), pp. 33 у I60.

iso Hörnle, Tatjana, Klingbeil, Stefan; Rothbar, Katja, cit. (n. 3I), p. 68. 
Alaggia, Ramona, Many ways of telling: expanding conceptualizations of child sexual abuse disclosure, en Child Abuse \& Neglect 28 (2004).

Aldunate Lizana, Eduardo, Derechos fundamentales (Santiago, Legal Publishing, 2008).

Asholt, Martin, Verjährung im Strafrecht: Zu den theoretischen, historischen und dogmatischen Grundlagen des Verhältnisses von Bestrafung und Zeit in SS 78 ff. StGB, (Tübingen, Mohr Siebeck, 20I6).

BADER, Jutta, Legitime Verletzteninteressen im Strafverfahren. Eine kritische Untersuchung der Rechtslage und Vorschläge de lege ferenda (Springer-Verlag, 20I9).

Beccaria, Cesare, Tratado de los delitos y de las penas (Madrid, Carlos III University of Madrid, 20I5).

Biblioteca del Congreso Nacional de Chile, Historia de la Ley 2I.I60. Declara imprescriptibles los delitos sexuales cometidos contra menores de edad. [Visible en internet: https://bit.ly/3kOWcRE]. ] (Fecha de último acceso: 02.12.20).

Cabezas Cabezas, Carlos, Imprescriptibilidad de la acción penal en delitos sexuales contra menores, en Revista de Derecho (Universidad Austral de Chile) 32 (2019), I.

Carlsmith, Kevin M., Wilson, Timothy D., Gilbert, Daniel T., The paradoxical consequences of revenge, en Journal of Personality and Social Psychology 95 (2008) 6.

Clancy, Susan, The Trauma Myth. The truth about the sexual abuse of children and its aftermath (New York, Basic Books, 2009).

Cury Urzúa, Enrique, Derecho Penal. Parte general (8. a edición, Santiago, Ediciones Universidad Católica de Chile, 2005).

Dallam, S. J., Gleaves, D. H., Cepeda-Benito, A., Silberg, J. L., Kraemer, H. C., \& Spiegel, D. The effects of child sexual abuse: Comment on Rind, Tromovitch, and Bauserman, en Psychological Bulletin 127 (200I) 6.

DíAz De Valdés Juliá, José Manuel, Igualdad constitucional y no discriminación (Valencia, Editorial Tirant Lo Blanch, 2019).

Etcheberry Orthusteguy, Alfredo, Derecho Penal. Parte general $\left(3 .{ }^{\mathrm{a}}\right.$ edición, Santiago, Editorial Jurídica de Chile, I999), II.

Feijoo Sánchez, Bernardo, Retribución y prevención general. Un estudio sobre la teoría de la pena y las funciones del derecho penal (Montevideo, Editorial B de F, 2007).

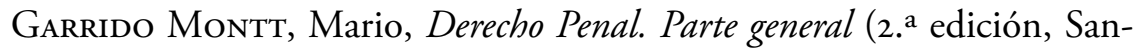
tiago, Editorial Jurídica de Chile, 2007), I.

Guzmán Dálbora, José Luis, Comentario a los arts. 93 a ros del Código Penal, en Politoff Lifschitz, Sergio y Ortiz Quiroga, Luis (dirs.), 
Texto y comentario del Código Penal chileno. Libro primero. Parte general (Santiago, Editorial Jurídica 2002), I.

Horvitz Lennon, María Inés y López Masle, Julián, Derecho Procesal Penal Chileno (Santiago, Editorial Jurídica de Chile, 2002), I.

Hörnle, Tatjana, Klingbeil, Stefan; Rothbar, Katja, Sexueller Missbrauch von Minderjährigen: Notwendige Reformen im Strafgesetzbuch. [Gutachten] erstellt für den Unabhängigen Beauftragten für Fragen des sexuellen Kindesmissbrauchs. (Berlín, 2013). [Visible en internet: https:// hoernle.rewi.hu-berlin.de/Gutachten_Strafrecht-2.pdf].

Jackson, Joshua C.; Choi, Virginia K., Gelfand, Michele J. (2019), Revenge: A Multilevel Review and Synthesis, en Annual Review of Psycho$\log 70$ (2019).

Jakoвs, Günther, Derecho Penal. Parte general. Fundamentos y teoría de la imputación (2. a edición, Madrid, Marcial Pons, 1997).

Matus Acuña, Jean Pierre, Código penal sistematizado con jurisprudencia (Santiago, Legal Publishing, 20II).

Matus Acuña, Jean Pierre; Ramírez Guzmán, María Cecilia, Manual de Derecho Penal Chileno. Parte General. Limites presupuestos y consecuencias de la responsabilidad penal en un sistema acusatorio (Valencia, Tirant lo Blanch, 2019).

MeIER, Bernd-Dieter, Strafrechtliche Sanktionen (2. ${ }^{a}$ edición, Springer, Berlín, 2006).

Mccoy, Monica L. y Keen, Stefanie M. (2014) Child Abuse and Neglect (2. ${ }^{a}$ edición, New York, Psychology Press, 2014).

Mcnally, Richard, Debunking Myths About Trauma and Memory, en Can J Psychiatry 50 (2005) I3.

Mannheim, Karl, El problema de las generaciones, en Revista Española de Investigaciones Sociológicas 62 (1993).

Novoa Monreal, Eduardo, Curso de Derecho Penal Chileno. Parte general (3. ${ }^{\text {a }}$ edición, Santiago, Editorial Jurídica de Chile, 20I9), II.

Oellerich, Thomas D., Rind, Tromovitch, and Bauserman: Politically incorrect-Scientifically correct, en Sexuality and Culture (2000) 4, Issue 2.

Oкамг, Paul, Sociopolitical Biases in the Contemporary Scientific Literature on Adult Human Sexual Behavior with Children and Adolescents, en Feierman, Jay R. (Ed.), Pedophilia. Biosocial Dimensions (New York, Springer Verlag, 1990).

Ondersma, Steven; Chaffin, Mark; Berliner, Lucy; Cordon, Ingrid; Goodman, Gail; Barnett, D. Sex with Children Is Abuse: Comment on Rind, Tromovitch, and Bauserman (1998), en Psychological Bulletin I27 (200I). 
Pacheco, Joaquín Francisco, El Código Penal concordado y comentado $\left(5 \cdot{ }^{\mathrm{a}}\right.$ edición, Madrid, Imprenta y Fundición de Manuel Tello, I88I), I.

Pacheco Gómez, Máximo, Teoría del derecho (4. ${ }^{\mathrm{a}}$ edición, Santiago, Editorial Jurídica, I993).

Pastor Alcoy, Francisco, Tratado de la prescripción penal (Barcelona, Editorial Atelier, 20I9).

Patihis, L.; Ho, L. Y.; Tingen, I. W., Lilienfeld, S. O. y Loftus, E. F., Are the "Memory Wars" Over? A Scientist-Practitioner Gap in Beliefs About Repressed Memory, en Psychological Science 25 (2014) 2.

Pendergrast, Mark, The Repressed Memory Epidemic. How It Happened and What We Need to Learn from It (Springer International Publishing, Springer International, 20I7).

Riego, Cristián, La expansión de las facultades de las víctimas en la Reforma Procesal Penal y con posterioridad a ella, en Politica Criminal 9 (20I4), I8.

Rind, Bruce; Tromovitch, Philip y Bauserman, Robert, The Validity and Appropriateness of Methods, Analyses, and Conclusions, en Rind et al. (1998): A Rebuttal of Victimological Critique From Ondersma et al. (200I) and Dallam et al. (200I), en Psychological Bulletin I27 (200I) 6.

Rind, Bruce; Tromovitch, Philip y Bauserman, Robert, A Meta-Analytic Examination of Assumed Properties of Child Sexual Abuse Using College Samples, en Psychological Bulletin I24 (1998), I.

Rodríguez Collao, Luis, Delitos sexuales (2. ${ }^{a}$ edición, Santiago, Editorial Jurídica de Chile, 20I8).

Roesler, T. y Weissmann, T., Telling the Secret. Adult Women Describe Their Disclosures of Incest. En Journal of Interpersonal Violence 9 (1994) 3.

Roxin, Claus, Derecho Procesal Penal $\left(25 .^{\mathrm{a}}\right.$ edición, Buenos Aires, Ediciones del Puerto, 2000).

Silva SÁnchez, Jesús María, Una crítica a las doctrinas penales de "la lucha contra la impunidad» $y$ del "derecho de la víctima al castigo del autor», en Revista de Estudios de la Justicia II (2009).

Thier, Andreas, Time, Law, and Legal History. Some Observations and Considerations, en Rechtsgeschichte. Legal History 25 (2017).

Vachon, David; Krueger, Robert; Rogosch, Fred y Cicchetti, Dante, Assessment of the Harmful Psychiatric and Behavioral Effects of Different Forms of Child Maltreatment, en JAMA Psychiatry 7. (2015).

Van Duin, E. M., Verlinden, E., Vrolijk-Bosschaart, T. F., Diehle, J., Verhoeff, A. P., Brilleslijper-Kater, S. N., y Lindauer, R. J.L., Sexual abuse in very young children: A psychological assessment in the 
Amsterdam Sexual Abuse Case Study, en European Journal of Psychotraumatology 9 (2018) I, Article I503524. [Visible en internet: https://doi.or g/IO.1080/20008198.2018.1503524].

Vega, A; Romo, V; Franco, D. y Pérez, M., Develación de las experiencias de agresión sexual de presuntas víctimas adultas: una propuesta comprensiva, en Huellas. Cuadernos de Criminodinámicas y Fenómenos Emergentes 2 (2016).

Vera, Robustiano, Código Penal de la República de Chile comentado (Santiago, Imprenta de P. Cadot y $\mathrm{C}^{\mathrm{a}}$, I883).

Vicente y Caravantes, José, Código penal reformado: Comentado novísimamente, precedido de una breve reseña histórica del derecho penal de España, y seguido de tablas sinópticas (Madrid, Librerías de Ángel Calleja, I85I).

Walter, Tonio, Vergeltung als Strafzweck. Prävention und Resozialisierung als Pflichten der Kriminalpolitik, en ZIS 7 (2OII).

Weigend, Thomas, „Die Strafe für das Opfer«? Zur Renaissance des Genugtuungsgedankens im Straf- und Strafverfahrensrecht, en Zeitschrift für rechtswissenschaftliche Forschung (Baden-Baden, 2010).

Yuseff Sotomayor, La prescripción penal ( $3 .^{\mathrm{a}}$ edición, Editorial Jurídica de Chile, Santiago, 20I8).

\section{SOBRE El AUTOR}

Pablo Castillo Montt es abogado, Dr. Iur., Ll.M. Albert-Ludwigs-Universität Freiburg, Alemania. Profesor investigador del Centro de Justicia Constitucional de la Facultad de Derecho de la Universidad del Desarrollo. Su correo electrónico es pablocastillomontt@gmail.com. 